\title{
The Design and Testing of a Dual Fiber Textile Matrix for Accelerating Surface Hemostasis
}

\author{
Thomas H. Fischer ${ }^{1}$, John N. Vournakis ${ }^{2}$, James E. Manning ${ }^{3}$, Shane L. McCurdy ${ }^{3}$, Preston \\ B. Rich ${ }^{4}$, Timothy C. Nichols ${ }^{1}$, Christopher M. Scull ${ }^{1}$, Marian G. McCord ${ }^{5,6}$, Joseph A. \\ Decorta $^{6}$, Peter C. Johnson ${ }^{6}$, and Carr J. Smith ${ }^{1,6}$ \\ ${ }^{1}$ Department of Pathology and Laboratory Medicine, University of North Carolina at Chapel Hill, \\ Chapel Hill, North Carolina \\ ${ }^{2}$ Marine Polymer Technologies, Danvers, Massachusetts \\ ${ }^{3}$ Department of Emergency Medicine, University of North Carolina at Chapel Hill, Chapel Hill, \\ North Carolina \\ ${ }^{4}$ Department of Surgery and Anesthesiology, University of North Carolina at Chapel Hill, Chapel \\ Hill, North Carolina \\ ${ }^{5}$ Department of Textile Engineering, Chemistry and Science, North Carolina State University, \\ Raleigh, North Carolina \\ ${ }^{6}$ Entegrion, Inc., Research Triangle Park, North Carolina
}

\section{Abstract}

The standard treatment for severe traumatic injury is frequently compression and application of gauze dressing to the site of hemorrhage. However, while able to rapidly absorb pools of shed blood, gauze fails to provide strong surface (topical) hemostasis. The result can be excess hemorrhage-related morbidity and mortality. We hypothesized that cost-effective materials (based on widespread availability of bulk fibers for other commercial uses) could be designed based on fundamental hemostatic principles to partially emulate the wicking properties of gauze while concurrently stimulating superior hemostasis. A panel of readily available textile fibers was screened for the ability to activate platelets and the intrinsic coagulation cascade in vitro. Type $\mathrm{E}$ continuous filament glass and a specialty rayon fiber were identified from the material panel as accelerators of hemostatic reactions and were custom woven to produce a dual fiber textile bandage. The glass component strongly activated platelets while the specialty rayon agglutinated red blood cells. In comparison with gauze in vitro, the dual fiber textile significantly enhanced the rate of thrombin generation, clot generation as measured by thromboelastography, adhesive protein adsorption and cellular attachment and activation. These results indicate that hemostatic textiles can be designed that mimic gauze in form but surpass gauze in ability to accelerate hemostatic reactions.

\section{Keywords}

Surface hemostasis; platelets; intrinsic coagulation; red blood cell agglutination 


\section{INTRODUCTION}

Despite considerable progress in understanding the patho-physiological processes involved in surface (topical) hemostasis, there remains an unmet need for materials that can be applied to staunch bleeding at sites of hemorrhage. Traumatic injury is the leading cause of death in the United States for individuals under 44 years of age, claiming 100,000 lives each year. ${ }^{1,2}$ In approximately half of these cases, exsanguination is the cause of death, and roughly 50,000 additional patients survive hemorrhaging injuries only after massive red blood cell transfusion. ${ }^{2-4}$ The situation is equally critical in combat medical care. In a recent review of military casualties, the control of non-compressible bleeding was identified as the most important unmet need in military emergency medicine. ${ }^{5}$ Frequently the standard of care is use of a tourniquet to control "compressible" bleeding and the application of gauze to control the residual "noncompressible" bleeding. However, the haemostatic inefficiency of gauze is a major contributor to morbidity and mortality. The hypothesis is thus explored that an inexpensive alternative material could be designed which would surpass gauze in its ability to limit blood loss by providing superior surface hemostasis.

Two lines of evidence provide the rational for considering continuous filament glass thread as a potential component of a haemostatic material. First, platelets activate and adhere to glass. ${ }^{3,4}$ Binding to glass is a longstanding method for assessing platelet activity (e.g., see ref. 5). Consequently, glass vessels are generally avoided in the in vitro handling of platelets. Secondly, plasma proteins (Hageman Factor (FXII) and fibrinogen being wellstudied examples ${ }^{6}$ ) undergo chemical and physical adsorption processes on foreign surfaces. ${ }^{7}$ FXII is particularly important because it initiates humoral coagulation at the glass/ blood interface. ${ }^{8,9}$ Platelet activation and turnover of intrinsic coagulation are highly interrelated mechanisms, in part due to the role platelets play as a catalytic surface for assembly of the FVa/FXa complex for thrombin generation. Platelet activation by biomaterials (e.g., via integrin outside-in signaling, especially glycoprotein IIb/IIIa) can result in surface presentation of phosphatidylserine, an important component of catalytic complexes for thrombin generation. ${ }^{10,11}$ FXII is peripherally associated with the platelet surface, eliciting activation of the intrinsic coagulation pathway in the microenvironment of the cell. ${ }^{12,13}$ Although processes involving FXII that occur on the platelet surface are poorly understood, the net effect of the close relationship between FXIIa-mediated coagulation and platelet activation is synergistic for earlier initiation of fibrin polymerization. ${ }^{10}$ These two lines of evidence indicate that continuous filament glass might be a valuable component of a haemostatic textile.

The interaction of fluids with glasses is largely controlled by surface phenomena related to hydrophobicity, zeta potential and wettability. ${ }^{14,15}$ E-glass filaments have mildly hydrophilic surfaces, and are frequently modified for enhanced fluid spreading. ${ }^{16,17}$ The combination of low wicking and non-absorbency into the interior of the glass filaments precludes the use of this material as a single bandage component. Thus, a second type of more adsorptive fiber was sought to provide the absorptive and wicking capacity lacking in the glass filaments. In order to narrow the selection of the complementary fiber type, a panel of natural and synthetic fibers was tested for tendency to activate platelets and the intrinsic coagulation cascade. This analysis lead to the formulation and testing of a dual fiber material, trade named Stasilon ${ }^{\circledR}$ (Entegrion, Inc., Research Triangle Park, NC) that consists of continuous filament type E-glass and a specialty rayon. 


\section{MATERIALS AND METHODS}

\section{Materials}

Type E continuous filament glass, specialty rayon (bamboo viscose from bambusa textilis), and other natural and synthetic fibers were provided by Cheraw Mills, Inc. (Cheraw, SC). The dual fiber glass/specialty rayon textile fabric, Stasilon ${ }^{\circledR}$, was obtained from Entegrion, Inc. (Research Triangle Park, NC). Specialty rayon and glass fibers were manually separated from the dual fiber textile for some experiments. Gauze was sourced from Kimble, Inc. (Elmira, NY).

\section{Whole blood and platelet rich plasma isolation}

A volume of $4.25 \mathrm{ml}$ of peripheral blood from consenting healthy volunteers was drawn into a $5 \mathrm{ml}$ syringe that contained $0.75 \mathrm{ml}$ of $3.2 \%(\mathrm{w} / \mathrm{v})$ citrate, $\mathrm{pH}=7.4$. Platelet rich plasma was obtained by centrifuging the blood at $200 \mathrm{xg}$ for twenty minutes at room temperature as detailed elsewhere. ${ }^{18}$ The platelet concentration in the platelet rich plasma was measured with a Hiska haematological analyzer, and the platelet concentration was adjusted to 150,000 platelets $/ \mu \mathrm{l}$ by diluting the sample with platelet free plasma (obtained by centrifuging platelet rich plasma for $10 \mathrm{~min}$ at $30,000 \mathrm{xg}$, then retaining the supernatant).

\section{Thrombin generation kinetics}

The effect of fibers on the kinetics of thrombin generation in platelet rich plasma (at 150,000 platelets $/ \mu \mathrm{l}$ ) was investigated by following the hydrolysis of the thrombin substrate D-phepro-arg-ANSNH to yield a fluorescent reaction product as detailed elsewhere. ${ }^{19}$ A $300 \mu \mathrm{g}$ sample of each fiber was tested in $100 \mu$ platelet rich plasma in triplicate with the fluorogenic substrate D-phe-pro-arg-ANSNH. The time course for thrombin generation was initiated by adding $\mathrm{CaCl}_{2}$ (to achieve a $10 \mathrm{mM}$ final concentration) to each sample. The lag time for thrombin generation was defined as the time point at which the fluorescence increased $10 \%$ over the initial baseline value. Three independent measurements were performed with each fiber, and the resulting lag times were used to calculate average, standard deviation and $\mathrm{P}$ probability values.

\section{Characterization of adsorbed plasma proteins}

Glass, specialty rayon fiber, or gauze was incubated for 30 seconds at $50 \mathrm{mg} / \mathrm{ml}$ with plasma (platelet free) that contained $10 \mathrm{mM} \mathrm{CaCl}_{2}$. The materials were then removed and diluted in $50 \mathrm{ml}$ of citrated saline $(5.375 \mathrm{mM}$ citrate, $146 \mathrm{mM} \mathrm{NaCl}, \mathrm{pH}$ - 7.4). Bulk materials were diluted to $10 \mathrm{mg} / \mathrm{ml}$ in citated saline and centrifuged at $1000 \mathrm{xg}$. Pel-lets were resuspended for the same material concentration and re-centrifuged. After a total of five centifugational washes the final material pellets were suspended at $100 \mathrm{mg} / \mathrm{ml}$ in reduced electrophoretic sample buffer and then incubated for five minutes at $100^{\circ} \mathrm{C}$ to remove bound proteins from the materials. Electrophoresis was performed as detailed elsewhere ${ }^{20,21}$ on gels with $11 \%$ (w/v) polyacrylamide content. Selected bands were subjected to GC/mass spectrometry analysis for identification as described elsewhere. ${ }^{22}$

\section{Thromboelastography (TEG)}

TEG measurements were performed with a TEG-5000 Thromboelastograph Hemostasis Analyzer (Haemoscope Corporation, Niles, IL). The assays were initiated by adding $\mathrm{CaCl}_{2}$ (to achieve a final concentration of $10 \mathrm{mM}$ ) to the whole blood, then the mixture (330 ul) was immediately transferred to the TEG chamber contained $1 \mathrm{mg}$ of material in $20 \mu \mathrm{l}$ citrated saline. The final fiber concentration was thus $3.0 \mathrm{mg} / \mathrm{ml}$. Measurements were performed for two hours at $37^{\circ} \mathrm{C}$, and then relevant parameters were extracted from the 
"stiffness" curve. Three or four independent measurements were used to calculate average, standard deviation and $\mathrm{P}$ probability values.

\section{Scanning electron microscopy (SEM)}

SEM analysis of the materials was performed as detailed elsewhere. ${ }^{19,23}$ Briefly, whole peripheral blood from volunteers was allowed to flow directly from the venipuncture butterfly onto the dual-fiber textile, glass fibers, specialty rayon or gauze so that each material $\left(1 \mathrm{~cm}^{2}\right.$ pieces $)$ was covered with excess blood $(5 \mathrm{ml})$. The materials were allowed to incubate for twenty seconds with the blood, and then they were added to $50 \mathrm{ml}$ citrated saline with $1 \mathrm{mM}$ EGTA to quench haemostatic processes. All samples were allowed to settle for five minutes to separate the fiber matrix pieces from un-attached blood cells, and then the fibers were rediluted with citrated saline. This process was repeated two more times to free each sample of unbound blood cells. After twenty seconds of contact with blood and multiple cycles of dilution and material/blood cell complex settling, glutaraldehyde was added for $0.1 \%(\mathrm{w} / \mathrm{v})$ and the samples were allowed to incubate at room temperature for one hour. The samples were diluted $1 / 1(\mathrm{v} / \mathrm{v})$ with $4 \%$ paraformaldehyde for a final concentration of $2 \%$, and then more glutaraldehyde was added for a final concentration of $0.5 \%$. The initial stabilization step with $0.1 \%$ glutaraldehyde has been shown to minimize osmotically driven alterations in RBC morphology due to paraformaldehyde exposure. ${ }^{24}$ Samples were stored at $4^{\circ} \mathrm{C}$ overnight and then examined with a Cambridge S200 scanning electron microscope at $20 \mathrm{kV}$.

\section{Measurement of bound RBCs}

$10 \mathrm{mg}$ samples of the dual fiber textile materials and gauze were directly exposed to $1.0 \mathrm{ml}$ whole peripheral blood and washed as detailed for SEM. The samples were then placed in $10 \mathrm{ml}$ of distilled water with $1 \% \mathrm{TX}-100$ to release hemoglobin from bound RBCs. The samples were centrifuged at $10,000 \mathrm{xg}$ for five minutes, then the absorbance at $414 \mathrm{~nm}$ was measured to quantify the total amount of hemoglobin (and thus number of RBCs) associated with each material. Three independent measurements were performed with each material, then the averages and standard deviations were reported.

\section{Measurement of extent of RBC lysis due to material contact}

$10 \mathrm{mg}$ samples of dual fiber textile and gauze were exposed to $1.0 \mathrm{ml}$ whole peripheral blood as in the last two sections. After twenty seconds of exposure, the samples were centrifuged at 10,000 $\mathrm{xg}$ for five minutes to pellet blood cells and other materials. The optical density at $414 \mathrm{~nm}\left(\mathrm{OD}_{414}\right)$ was measured to quantify the amount of released hemoglobin in the supernatants. Standard curves were constructed by lysing suspensions of RBCs at defined hematocrits (measured with a Hiska haematological analyzer) to obtain reference $\mathrm{OD}_{414}$ values, and then a standard curve relating $\mathrm{OD}_{414}$ to number of $\mathrm{RBCs}$ was constructed and used to ascertain the number of RBCs bound to defined masses of the test materials. Three independent measurements were performed for each material and then an average and standard deviation were reported. This is the same method as detailed elsewhere. ${ }^{25,26}$

\section{Statistical Methods}

The statistical significance of differences between groups of parameters was characterized by calculating P probability values with the Student's t-test. A two-tail assumption was made, and the data sets under comparison were assumed to have unequal variances for a heteroscedastic analysis. Microsoft Excel was used to perform the numerical calculations. Statistical significance was inferred at a P value of 0.05 or less. 


\section{RESULTS}

Experiments proceeded in two stages. First, candidate materials for formulating the haemostatic textile were identified by measuring the ability of selected fibers to activate haemostatic processes in platelet rich plasma. Secondly, a dual fiber textile, Stasilon®, was prepared and analyzed to characterize haemostatic functionality. Details of these experiments follow.

\section{Activation of haemostatic system by candidate fibers}

A panel of common textile fibers was analyzed for their ability to activate platelets and accelerate turnover of the intrinsic (contact) coagulation pathway using a fluorogenic thrombin generation assay. The behavior of representative fibers in a fluorogenic thrombin generation assay is depicted in Figure 1. Exposure of the platelet rich plasma to type E continuous filament glass resulted in thrombin generation in approximately eight minutes. Specialty rayon was less prothrombogenic with thrombin generation occurring in 12 minutes, while gauze fiber was considerably slower at 17 minutes. The behavior of a more expansive panel of fibers is presented in Figure 2. Glass and specialty rayon were the first and second most thrombogenic materials tested, respectively. The lag time for thrombin generation was significantly shorter with glass and the specialty rayon than the other test materials ( $\mathrm{p}<0.05$ when triplicate measurements were compared). Chitin and gauze, which are components of marketed products for surface hemostasis, did not strongly accelerate thrombin generation. Based on these results, a prototype bandage was constructed from glass and the specialty rayon.

\section{Plasma protein adsorption to materials}

The set of plasma proteins that tightly bind to glass, the specialty rayon and gauze was characterized by incubating plasma with each material, exhaustively washing with citrated saline, and then performing protein electrophoresis. Figure 3, which is representative of three independent determinations, show that each material bound a specific subset of plasma proteins. Based on the overall density of the protein stain, glass and the specialty rayon bound more total proteins than gauze, including several proteins that were identified with $\mathrm{GC} /$ mass spectrometry analysis as the $70 \mathrm{kDa} \operatorname{IgM}$ heavy $(\mu)$ chain, $67 \mathrm{kDa}$ serum albumin, and the $50-60 \mathrm{kDa}$ fibrinogen chains.

\section{In vitro properties of the glass/specialty rayon dual fiber textile}

The results of the in vitro analysis of candidate materials lead to the selection of glass and specialty rayon for the components of the dual fiber textile product. A proprietary "modified crow's foot" weave was chosen from a dozen potential weaves because the "tightness" of this interlacement allows limited wicking to deliver hemostatic reaction components while retarding bulk fluid flow, to accelerate surface hemostatic reactions. The dual fiber matrix, type E glass and the specialty rayon were compared using thromboelastographic analysis with whole blood (see Figure 4a). This analysis was performed with the same amount of total material (for $3 \mathrm{mg} / \mathrm{ml}$ glass, specialty rayon, or glass + specialty rayon) in each cuvette. The dual fiber textile ( $\mathrm{R}=5.8 \pm 0.9 \mathrm{~min}, \mathrm{n}=4$ determinations) was found to accelerate fibrin clot formation in a statistically significant manner as compared to glass $(\mathrm{R}=8.8 \pm 1.3$ min, $\mathrm{n}=3$ determinations, $\mathrm{p}=0.00163$ compared to dual-fiber textile), specialty rayon $(\mathrm{R}=$ $9.1 \pm 1.5 \mathrm{~min}, \mathrm{n}=3$ determinations, $\mathrm{p}=0.0160$ compared to dual-fiber textile or saline negative control $(\mathrm{R}=14.9 \pm 2.7 \mathrm{~min}, \mathrm{n}=4$ determinations, $\mathrm{p}=0.0004$ compared to dualfiber textile). The coagulation activation observed with the saline samples reflected the interaction with the TEG cuvette surface material. Since the same amount of total material was in each cuvette, the acceleration of hemostasis measured with the dual fibers reflects a synergistic effect, not an effect that is additive for the two materials. 
Analysis of the dual fiber matrix and gauze by scanning electron microscopy (SEM) following contact with excess peripheral blood (see Figure 5a, which is representative of five independent SEM examinations) showed the glass/specialty rayon matrix tightly binding significant numbers of RBCs, while these cells only sparsely covered the gauze matrix. Glass filaments are recognizable as cylindrical filaments, while the specialty rayon has a more complex "ribbed" cross-sectional geometry. SEM analysis of glass and specialty rayon separately indicated that glass robustly bound platelets in a highly activated morphology, while the specialty rayon primarily bound agglutinated RBCs (see Figure $5 b$ ). Quantification of the number of RBCs on each matrix (see Figure 6) revealed that the dual fiber textile bound approximately three times as many RBCs per unit weight as gauze, and that the RBC binding to the dual fiber matrix was due to the specialty rayon content.

Significant lysis of RBCs did not occur (data not shown). These results indicate that the two materials in the Stasilon ${ }^{\circledR}$ matrix impart different but synergistic properties for accelerated clot formation.

\section{DISCUSSION}

This study demonstrates that fundamental principles underlying haemostatic processes can be applied to design economical materials that accelerate hemostatic reactions for surface hemostasis, the selection of glass and specialty rayon bamboo being based on ability to accelerate platelet activation and turnover of the humoral coagulation cascade. The relevant econometric consideration is that the glass and bamboo rayon are readily available fibers that have extensive non-medical commercial uses. Stasilon ${ }^{\circledR}$ received clearance by the United States Food and Drug Administration for broad-based use in surgical and emergency medicine in December of 2007 (United States Food and Drug Administration 510(k) number K072890). Based on comparison with gauze in porcine hemorrhage studies, the FDA cleared Stasilon ${ }^{\circledR}$ with an indication as a hemostatic wound dressing. Clinical trials for various surgical and emergency medicine indications have subsequently been initiated to address the question of the clinical significance of accelerated hemostasis with respect to blood loss and associated morbidity and mortality.

Acceleration of hemostatic reactions has been a factor in the design of other products for surface hemostasis. For example, maximization of surface area for increased specific reactivity (catalytic surface activity/unit mass) is incorporated into the design of $\beta$-poly-Nacetyl glucosamine nanofiber-based products (Syvek® patch, Marine Polymer Technologies, Danvers, MA). Similarly, the ability to accelerate activation of factor XII and the intrinsic coagulation cascade was a design element of zeolite-based products ${ }^{27,28}$ (e.g., QuickClot ${ }^{\circledR}$, Z-Medica, Inc., Wallingford, CN) and smectite clay-based formulations ${ }^{29}$ (Woundstat ${ }^{\circledR}$, Traumacure, Inc., Bethesda, MA). As is the case with the dual fiber matrix, these types of products outperform gauze in animal testing as well as human field use. ${ }^{30}$

The role of the glass filaments in Stasilon ${ }^{\circledR}$ are relatively well-understood, with three earlier findings defining some of the functions of the glass fibers in the dual-fiber matrix. First, platelets activate and adhere to glass. ${ }^{31}$ Secondly, FXII (Hageman Factor) was discovered and found to be important in initiating humoral coagulation at the glass/blood interface..$^{8,9}$ Third, plasma proteins ${ }^{32-34}$ (FXII ${ }^{9}$ and fibrinogen ${ }^{35-37}$ being well-studied examples), undergo chemical and physical adsorption processes on foreign surfaces ${ }^{7}$ inducing the formation of a "Vroman" layer. ${ }^{38,39}$ These three fundamental findings were subsequently extended by elucidating parts of the mechanisms through which adsorbed fibrinogen activates platelets. $4,32-34,38,40,41$ Artificial surface-bound fibrinogen can behave like a "biosensor" for platelets and is associated with an enthalpy readily detected with calorimetry. ${ }^{42}$ Furthermore, the adsorbed fibrinogen has an altered conformation as judged by atomic force microscopy ${ }^{35}$ and can occlude monoclonal antibody binding sites. ${ }^{43}$ Surface bound 
fibrinogen has been reported to undergo a poorly defined process termed "conversion", 6 that might involve disassociation from the surface, a conformational change and/or occlusion by prekallikrein or other proteins. ${ }^{43} \mathrm{~A}$ result of the conformational distortion on glass ${ }^{44}$ and other hydrocarbon polymer-coated materials ${ }^{45-47}$ is that contact with platelets results in their adhesion and activation. Current understanding of integrin outside-in signaling processes suggests that integrins bind to domain(s) on the adsorbed fibrinogen molecule that conformationally resemble fibrin, and then cluster on the platelet membrane to organize cytoskeletal-related signaling machinery for activation of outside-in signaling. ${ }^{48}$ The observation (Figure 3 ) that material components of the dual fiber bandage tightly bind fibrinogen chains indicate incorporation of these molecules into the Vroman layer are important in the haemostatic function of Stasilon ${ }^{\circledR}$.

The role of the bamboo viscose rayon in the function of the dual fiber bandage is less well understood. However, it is reasonable to hypothesize that three surface processes occur: an initial selective adsorption event for the formation of a Vroman layer; ${ }^{38,39}$ a conformational distortion of the adsorbed proteins; and an interaction with platelets and the intrinsic coagulation cascade that is in part a consequence of the conformational alterations of the adsorbed proteins. The hydrophilic nature of specialty rayon probably plays an important role in driving these three processes. As is the case with many regenerated cellulosic fibers, the properties of bamboo viscose rayon are to some extent dependent on the pulp composition, e.g., hemicellulosic content, but these relationships are not clearly defined. ${ }^{49,50}$ Bamboo viscose is morphologically similar to conventional viscose. The cross-section has an irregular "popcorn" shape and longitudinal striations with long surface cracks characterize the surface. These striations and cracks increase the effective surface area of the fiber, and are believed to contribute to the high water absorptivity and retention capabilities of this material. ${ }^{51}$ Regenerated cellulosic fibers are porous materials that contain both crystalline and amorphous regions that are characterized by different moisture absorption and retention capabilities. Crystalline regions are highly ordered and have low absorptivity, while amorphous domains are highly disordered and have greater availability of sites for molecular diffusion. The crystallinity of bamboo viscose (cellulose II) is lower than that of standard viscose or lyocell. ${ }^{52}$ The chemical and structural aspects of specialty rayon that make this fiber more prothrombogenic than other cellulosic fibers, such as rayon and cotton in gauze, are not understood.

An unanticipated finding was that RBCs strongly absorb to the specialty rayon fibers in Stasilon ${ }^{\circledR}$. This type of RBC agglutination effect has recently been reported to occur when poly-N-acetyl glucosamine based products for surface hemostasis contact blood, and is associated with the exposure of surface phosphotidylserine on the RBCs and the generation of a prothrombotic membrane. ${ }^{25,26}$ The physical bases of these interactions are not completely understood, but, as is the case with poly- $\mathrm{N}$-acetyl glucosamine, potentially involves an interaction of the cellulosic material with band 3 and other surface proteins on the erythrocytes. TEG analysis (see Figure 4) showed that glass and specialty rayon synergize to activate fibrin polymerization in whole blood faster than either material alone (given a similar mass of total material). This result suggests that RBC agglutination on the rayon could accelerate platelet activation on glass for faster generation of thrombin; the agglutinated RBCs might release a factor (e.g., prostaglandin, free hemoglobin, reactive oxygen species) that synergize with the glass surface, as a "solid agonist", for acceleration of platelet activation reactions. Alternatively, the fluid transport properties of the specialty rayon, while in close physical contact with the glass interfacial surface, could play a role in the synergistic acceleration of hemostasis.

An important phenomena that is under investigation independent of the work presented here is an increase in flow resistance that occurs when RBCs aggregate on the dual fiber matrix. 
The weave of the dual fiber textile was chosen to provide mild wicking (to deliver hemostatic components for reaction) but also resistance to bulk fluid flow (to minimize hemorrhage). RBC agglutination is likely to further slow the flow of blood through the dual fiber textile as compared to gauze in the first few seconds after exposure to blood. Based on a first-principle consideration of the behavior of reactive systems under flow, slowing of fluid motion is anticipated to increase the concentration of activated coagulation factors in the microenvironment of catalytic textile surfaces. ${ }^{53-55}$

Existing knowledge of how hemostatic systems interact with glass and the data presented here suggests that the dual fiber matrix functions through at least three mechanisms: turnover of the intrinsic coagulation cascade, activation of platelets and red blood cell agglutination. The product's multifactorial hemostatic mechanisms for action suggest that this matrix will be useful in patients that are coagulopathic due to a variety of underlying conditions, including hemorrhagic shock (trauma-induced coagulopathy), hemophilia, thrombocytopenia, and/or treatment with anticoagulation or anti-platelet therapies. This hypothesis is supported by a recent case study in which the dual fiber bandage effectively provided hemostasis in an aplastic anemic patient with refractory hemorrhage after ingrown toenail reconstruction. ${ }^{56}$ The clinical utility of the dual fiber product in coagulopathic, as well as hemostatically competent, patients awaits the results of studies (that are currently underway) that are explicitly designed with endpoints of blood loss, transfusion avoidance, morbidity and mortality.

\section{Acknowledgments}

Contract grant sponsor: North Carolina Biotechnology Center (Collaborative Research grant).

The authors are indebted to Cheraw Mills, Trinity Healthcare, and Carolina Narrow Fabrics for their technical support.

\section{REFERENCES}

1. CDC. Center for Disease Control Injury Mortality Report. 2002. http://webapp.cdc.gov/sasweb/ncipc/leadcaus10.html

2. Heron, M.; Smith, BL. National Vital Statistics Reports (CDC) Deaths: Leading Causes for 2003. 2007. http:/0-www.cdc.gov.mill1.sjlibrary.org/nchs/data

3. Rozenberg MC, Stormorken H. Comparison of glass adhesiveness and rate of aggregation of blood platelets. Scand J Clin Lab Invest. 1967; 19(1):82-5. [PubMed: 6031325]

4. Zucker MB, Vroman L. Platelet adhesion induced by fibrinogen adsorbed onto glass. Proc Soc Exp Biol Med. 1969; 131(2):318-20. [PubMed: 5305877]

5. Cooper RG, Cornell CN, Muhrer ME, Garb S. Platelet adhesion in bleeder swine measured by glass bead column. Tex Rep Biol Med. 1969; 27(4):955-61. [PubMed: 5310287]

6. Vroman L, Adams AL, Fischer GC, Munoz PC. Interaction of high molecular weight kininogen, factor XII, and fibrinogen in plasma at interfaces. Blood. 1980; 55(1):156-9. [PubMed: 7350935]

7. Silberberg A. The absorption of flexible macromolecules Part I: The isolated macromolecule at a plane interface. J. Physical Chem. 1962; 66:1872-1883.

8. Ratnoff OD, Margolius A Jr. Hageman trait: an asymptomatic disorder of blood coagulation. Trans Assoc Am Physicians. 1955; 68:149-54. [PubMed: 13299324]

9. Ratnoff OD, Rosenblum JM. Role of Hageman factor in the initiation of clotting by glass; evidence that glass frees Hageman factor from inhibition. Am J Med. 1958; 25(2):160-8. [PubMed: 13559269]

10. Fischer TH, Thatte HS, Nichols TC, Bender-Neal DE, Bellinger AD, Vournakis JN. Synergistic platelet integrin signaling and factor XII activation in poly-N-acetyl glucosamine fiber-mediated hemostasis. Biomaterials. 2005; 26(27):5433-43. [PubMed: 15860200] 
11. Thatte HS, Zagarins S, Khuri SF, Fischer TH. Mechanisms of poly-N-acetyl glucosamine polymermediated hemostasis: platelet interactions. J Trauma. 2004; 57(1 Suppl):S13-21. [PubMed: 15280745]

12. Iatridis PG, Ferguson JH, Iatridis SG. Surface Factor Mechanisms in Relation to Blood Platelets: Evidence That Activated Hageman Factor Is Present on the Surface of Platelets. Thromb Diath Haemorrh. 1964; 11:355-71. [PubMed: 14194111]

13. Shibayama Y, Reddigari S, Kaplan AP. Interactions of factor XII with platelets and endothelial cells. Immunopharmacology. 1996; 32(1-3):24-7. [PubMed: 8796261]

14. Lopes MA, Monteiro FJ, Santos JD, Serro AP, Saramago B. Hydrophobicity, surface tension, and zeta potential measurements of glass-reinforced hydroxyapatite composites. J Biomed Mater Res. 1999; 45(4):370-5. [PubMed: 10321710]

15. Voigt A, Wolf H, Lauckner S, Neumann G, Becker R, Richter L. Electrokinetic properties of polymer and glass surfaces in aqueous solutions: experimental evidence for swollen surface layers. Biomaterials. 1983; 4(4):299-304. [PubMed: 6640058]

16. Andrade AL, Ferreira JM, Domingues RZ. Surface modifications of alumina-silica glass fiber. J Biomed Mater Res B Appl Biomater. 2004; 70(2):378-83. [PubMed: 15264322]

17. Metwalli E, Haines D, Becker O, Conzone S, Pantano CG. Surface characterizations of mono-, di-, and tri-aminosilane treated glass substrates. J Colloid Interface Sci. 2006; 298(2):825-31. [PubMed: 16631784]

18. Fischer TH, Bode AP, Parker BR, Russell KE, Bender DE, Ramer JK, Read MS. Primary and secondary hemostatic functionalities of rehydrated, lyophilized platelets. Transfusion. 2006; 46(11):1943-50. [PubMed: 17076850]

19. Fischer TH, Bode AP, Demcheva M, Vournakis JN. Hemostatic properties of glucosamine-based materials. J Biomed Mater Res A. 2007; 80(1):167-74. Fischer, 2006 1544. [PubMed: 17001651]

20. Laemmli UK. Cleavage of structural proteins during the assembly of the head of bacteriophage T4. Nature. 1970; 227(259):680-5. [PubMed: 5432063]

21. Fischer T, Thatte H, Nichols T, Bender-Neal D, Bellinger D, Vournakis J. Platelet Integrin Signaling and Factor XII Activation are Synergistic Mechanisms for Poly-N-acetyl Glucosamine Fiber Mediated Hemostasis. Biomaterials. 2004 Submitted.

22. Fischer, T.; Smith, CJ.; Vournakis, JN. Mechanisms for the interaction of foreign materials with hemostatic systems. In: Columbus, F., editor. New Research on Biomaterials. Nova Science Publishers, Inc.; Hauppauge, NY: 2006.

23. Sanders WE, Read MS, Reddick RL, Garris JB, Brinkhous KM. Thrombotic thrombocytopenia with von Willebrand factor deficiency induced by botrocetin. An animal model. Lab Invest. 1988; 59(4):443-52. [PubMed: 3262788]

24. Fischer TH, Robbins ME, Bode AP, Nichols TC, Bellinger DE, Schoenfisch MH. Evidence that rehydrated, lyophilized red blood cells are sufficiently deformable for normal microcirculation transit. Microsc Res Tech. 2004; 65(1-2):62-71. [PubMed: 15570582]

25. Fischer TH, Valeri CR, Smith CJ, Scull CM, Merricks EP, Nichols TC, Demcheva M, Vournakis JN. Non-classical processes in surface hemostasis: mechanisms for the poly-N-acetyl glucosamine-induced alteration of red blood cell morphology and surface prothrombogenicity. Biomed Mater. 2008; 3(1):15009.

26. Smith CJ, Vournakis JN, Demcheva M, Fischer TH. Differential effect of materials for surface hemostasis on red blood cell morphology. Microsc Res Tech. 2008; 71(10):721-9. [PubMed: 18570337]

27. Ahuja N, Ostomel TA, Rhee P, Stucky GD, Conran R, Chen Z, Al-Mubarak GA, Velmahos G, Demoya M, Alam HB. Testing of modified zeolite hemostatic dressings in a large animal model of lethal groin injury. J Trauma. 2006; 61(6):1312-20. [PubMed: 17159671]

28. Neuffer MC, McDivitt J, Rose D, King K, Cloonan CC, Vayer JS. Hemostatic dressings for the first responder: a review. Mil Med. 2004; 169(9):716-20. [PubMed: 15495727]

29. Ward KR, Tiba MH, Holbert WH, Blocher CR, Draucker GT, Proffitt EK, Bowlin GL, Ivatury RR, Diegelmann RF. Comparison of a new hemostatic agent to current combat hemostatic agents in a Swine model of lethal extremity arterial hemorrhage. J Trauma. 2007; 63(2):276-83. discussion 283-4. [PubMed: 17693824] 
30. Pusateri AE, Holcomb JB, Kheirabadi BS, Alam HB, Wade CE, Ryan KL. Making sense of the preclinical literature on advanced hemostatic products. J Trauma. 2006; 60(3):674-82. [PubMed: 16531876]

31. Barr H. The stickiness of platelets. Lancet. 1941; 238(6168):609-610.

32. Stouffer JE, Lipscomb HS. Reversibel binding of ACTH to a glass surface. Endocrinology. 1963; 72:91-4. [PubMed: 13984461]

33. Lissitzky S, Roques M, Benevent MT. Influence of proteins on the adsorption of I 131-labelled Lthyroxin on glass. C R Seances Soc Biol Fil. 1960; 154:396-9. [PubMed: 14417478]

34. Bull HB. Adsorption of bovine serum albumin on glass. Biochim Biophys Acta. 1956; 19(3):46471. [PubMed: 13315306]

35. Sit PS, Marchant RE. Surface-dependent conformations of human fibrinogen observed by atomic force microscopy under aqueous conditions. Thromb Haemost. 1999; 82(3):1053-60. [PubMed: 10494763]

36. Rapoza RJ, Horbett TA. Postadsorptive transitions in fibrinogen: influence of polymer properties. J Biomed Mater Res. 1990; 24(10):1263-87. [PubMed: 2283349]

37. Perez-Luna, VH.; Horbett, TA.; Ratner, BD. Developing correlations between fibrinogen adsorption and surface properties using multivariate statistics. Student Research Award in the Doctoral Degree Candidate Category, 20th annual meeting of the Society for Biomaterials; Boston, MA. April 5-9; 1994. J Biomed Mater Res 1994;28(10):1111-26

38. Vroman L, Adams AL. Possible involvement of fibrinogen and proteolysis in surface activation. A study with the recording ellipsometer. Thromb Diath Haemorrh. 1967; 18(3-4):510-24. [PubMed: 4232164]

39. Vroman L. Effects of Hydrophobic Surfaces Upon Blood Coagulation. Thromb Diath Haemorrh. 1964; 10:455-93. [PubMed: 14113384]

40. Vroman L, Adams AL. Effect of heparin on reactions at aminated polymer-blood interfaces. J Colloid Interface Sci. 1969; 31(2):188-95. [PubMed: 5387996]

41. Scarborough DE, Mason RG, Dalldorf FG, Brinkhous KM. Morphologic manifestations of bloodsolid interfacial reactions. A scanning and transmission electron microscopic study. Lab Invest. 1969; 20(2):164-9. [PubMed: 5764788]

42. Chiu TH, Nyilas E, Lederman DM. Thermodynamics of native protein/foreign surface interactions. IV. Calorimetric and microelectrophoretic study of human fibrinogen sorption onto glass and LTIcarbon. Trans Am Soc Artif Intern Organs. 1976; 22:498-513. [PubMed: 951870]

43. Lindon JN, McManama G, Kushner L, Merrill EW, Salzman EW. Does the conformation of adsorbed fibrinogen dictate platelet interactions with artificial surfaces? Blood. 1986; 68(2):35562. [PubMed: 3730606]

44. Coller BS, Peerschke EI, Scudder LE, Sullivan CA. A murine monoclonal antibody that completely blocks the binding of fibrinogen to platelets produces a thrombasthenic-like state in normal platelets and binds to glycoproteins IIb and/or IIIa. J Clin Invest. 1983; 72(1):325-38. [PubMed: 6308050]

45. Goodman SL, Cooper SL, Albrecht RM. Integrin receptors and platelet adhesion to synthetic surfaces. J Biomed Mater Res. 1993; 27(5):683-95. [PubMed: 8390998]

46. De Scheerder I, Verbeken E, Van Humbeeck J. Metallic surface modification. Semin Interv Cardiol. 1998; 3(3-4):139-44. [PubMed: 10406683]

47. Nagai H, Handa M, Kawai Y, Watanabe K, Ikeda Y. Evidence that plasma fibrinogen and platelet membrane GPIIb-IIIa are involved in the adhesion of platelets to an artificial surface exposed to plasma. Thromb Res. 1993; 71(6):467-77. [PubMed: 8134906]

48. Juliano RL. Signal transduction by cell adhesion receptors and the cytoskeleton: functions of integrins, cadherins, selectins, and immunoglobulin-superfamily members. Annu Rev Pharmacol Toxicol. 2002; 42:283-323. [PubMed: 11807174]

49. Chae D, Choi B, Oh Y. Effect of cellulose pulp type on the mercerizing behavior and physical properties of lyocell fibers. Textile Research Journal. 2003; 73:541.

50. Seheb, DN.; Jog, JP. Advances in Polymer Technology. John Wiley and Sons, Inc.; New York: 1999. Natural Fibers Polymer Composites: A Review; p. 351-363. 
51. Siroka B, Noisternig M, Griesser UJ, Bechtold T. Characterization of cellulosic fibers and fabrics by sorption/desorption. Carbohydr Res. 2008; 343(12):2194-2199. [PubMed: 18314097]

52. Xu Y, LU Z, Tang R. Structure and thermal properties of bamboo viscose, Tencel and conventional viscose fiber. Journal of Thermal Analysis and Calorimetry. 2007; 88(1):197-201.

53. Basmadjian D. The effect of flow and mass transport in thrombogenesis. Ann Biomed Eng. 1990; 18(6):685-709. [PubMed: 2281887]

54. Harrison SE, Smith SM, Bernsdorf J, Hose DR, Lawford PV. Application and validation of the lattice Boltzmann method for modelling flow-related clotting. J Biomech. 2007; 40(13):3023-8. [PubMed: 17445820]

55. Nemerson Y, Turitto VT. The effect of flow on hemostasis and thrombosis. Thromb Haemost. 1991; 66(3):272-6. [PubMed: 1745996]

56. Schumacher SA, Fischer TH, Smith CJ. New haemostatic textile stopped refractory bleeding in an aplastic anaemia patient. Haemophilia. 2008 


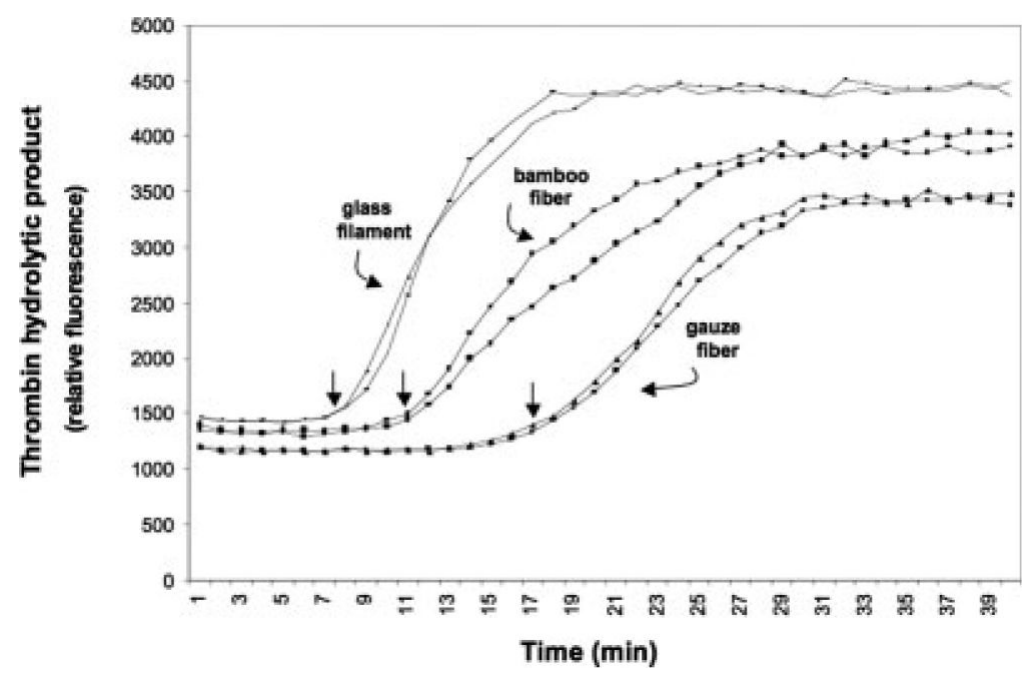

Figure 1.

Representative Thrombin Generation Curves- Duplicate samples (in separate wells of a 96 well plate) of glass, specialty rayon or gauze fibers were placed in platelet rich plasma containing a fluorogenic thrombin substrate. The thrombin generation time course was initiated by adding calcium. Arrows indicate the times for thrombin generation. Experimental details are presented in the Materials and Methods section. 


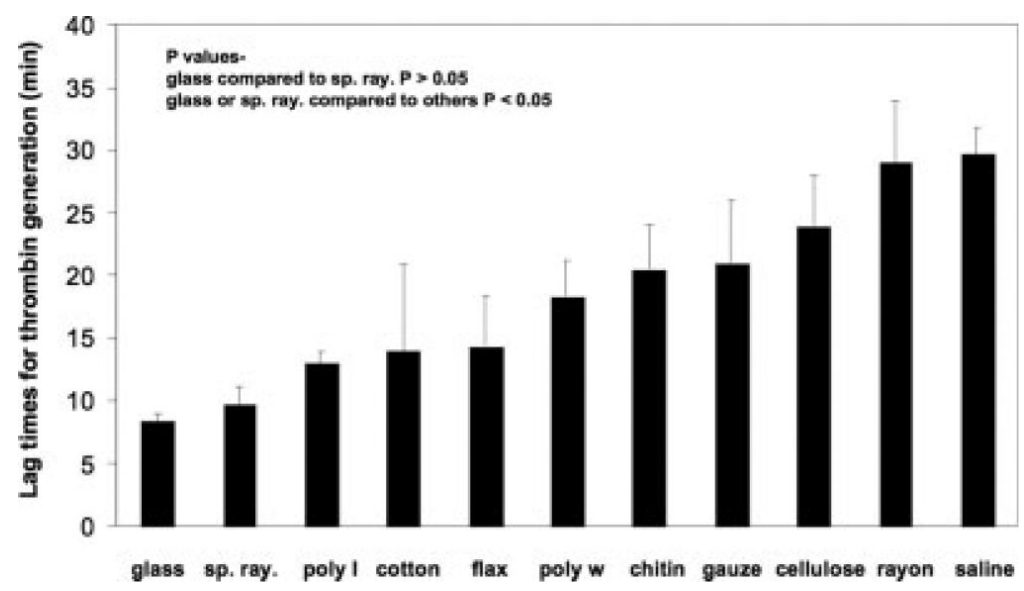

Figure 2.

Times for Thrombin Generation- The indicated fibers were tested to measure times for thrombin generation in platelet rich plasma. Error bars represent the standard deviation of three independent measurements, where each independent measurement is an average value of the lag time obtained from the curves from two wells as depicted in Figure 1. 


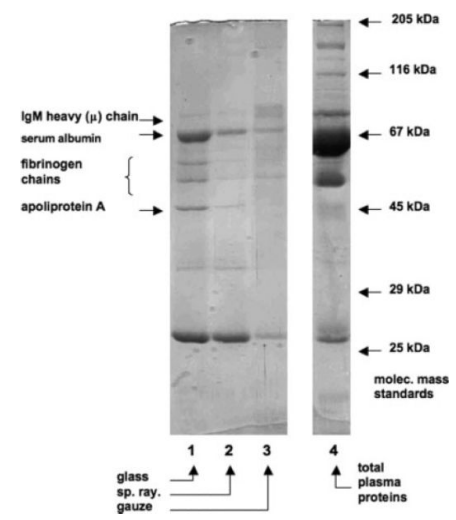

Figure 3.

Protein Adsorption to Materials- Glass (lane 1), specialty rayon (lane 2) or gauze (lane 3) was incubated for 30 seconds with excess calcified normal human plasma. The materials were bulk washed to remove unbound proteins, and then subjected to SDS-polyacrylamide gel electrophoresis to characterize bound proteins as detailed in the Materials and Methods section. Selected bands were identified with Western and/or GC-mass spectroscopic analysis as indicated. The depicted results are typical from three independent determinations. 

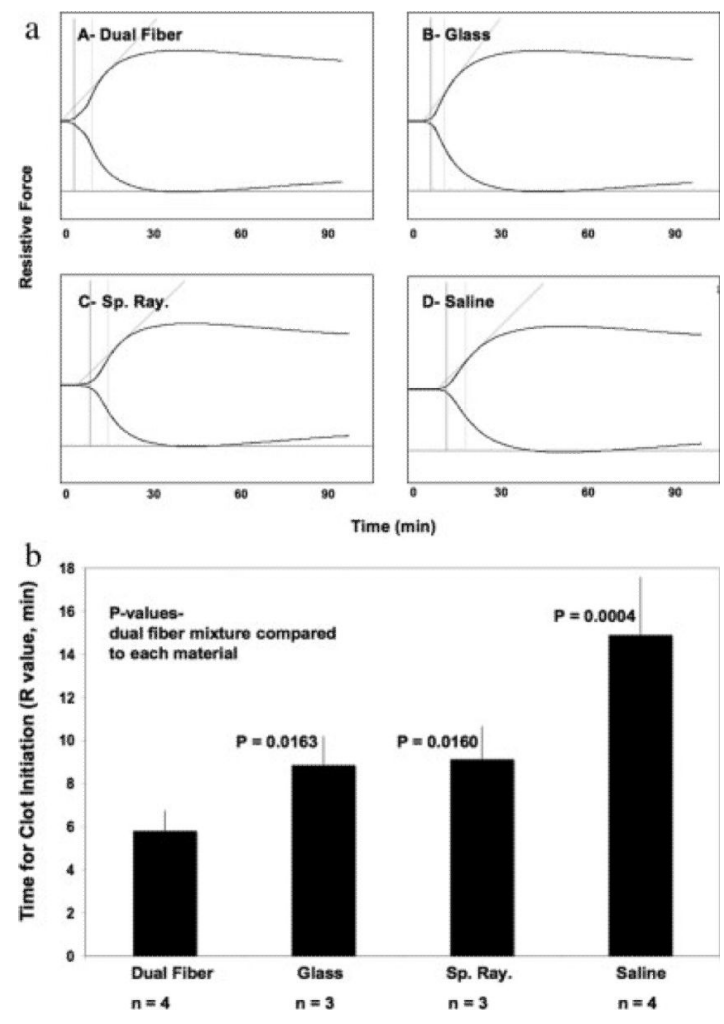

Figure 4.

(a) Thromboelastographic Analysis of Materials- Equal masses of dual fiber textile, glass or specialty rayon or gauze was placed in the Thromboelastographic cuvette with citrated saline and then whole blood and calcium as added to initiate clot formation. Citrated saline without material was run as a negative control. Experimental details are presented in the Materials and Methods section. (b) The times for beginning of clot formation (R values) were obtained from the force generation curves from three or four independent determinations (n values as indicated in the Figure) with different donors (see text for details). Standard deviations are depicted and related p-values for the difference between the dual fiber and other test materials are listed. 

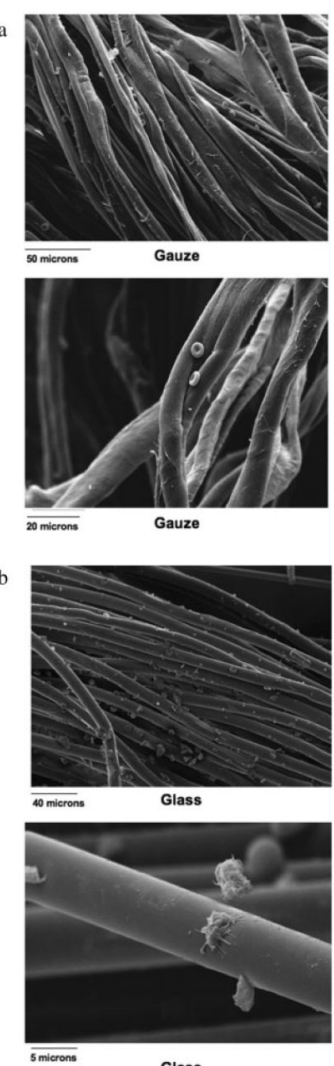

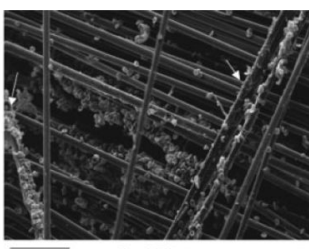

Dual Fiber
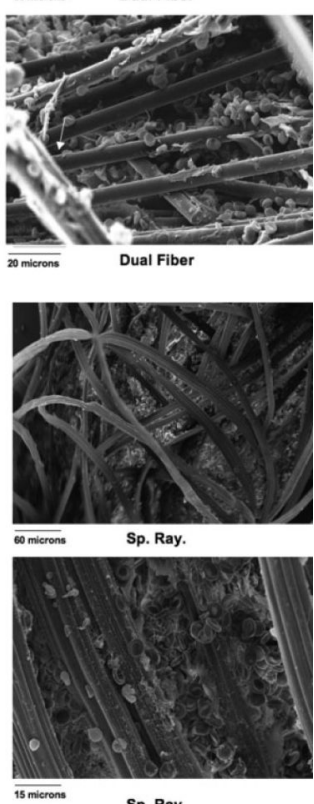

Figure 5.

(a) Comparison of Blood Cells on Dual Fiber and Gauze- Dual fiber textile or gauze was saturated with excess peripheral blood, washed, and then examined with scanning electron microscopy as detailed in the Materials and Methods section. The white arrows in the right two dual fiber panels indicate specialty rayon fibers. (b) Glass filament or specialty rayon was saturated with excess peripheral blood, washed, and then examined with scanning electron microscopy as detailed in the Materials and Methods section. 


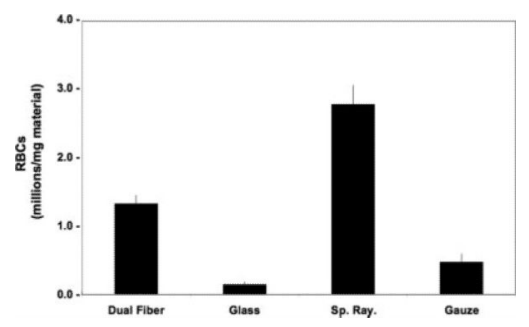

Figure 6.

Binding of Red Blood Cells with Materials- Dual fiber textile, glass, specialty rayon or gauze was saturated with excess peripheral blood, washed, and then the number of bound RBCs was measured as described in the Materials and Methods section. Error bars represent the standard deviation from triplicate measurements. 